\title{
Contraste de un modelo de fiabilidad social en función de emociones relativas a la seguridad pública
}

\section{Contrast of a reliability model of social function of emotions for public safety}

\author{
Javier Carreón Guillén \\ Jorge Hernández Valdés \\ UNAM-Escuela Nacional \\ María de Lourdes Morales Flores \\ Cruz García Lirios \\ UAEM, unidad de Huehuetoca
}

de Trabajo Social (ENTS)

\author{
José Marcos Bustos Aguayo \\ UNAM-Facultad de Estudios \\ Superiores Zaragoza
}

\section{Resumen}

Estado y sociedad han transitado de relaciones coercitivas totalitarias hasta una gobernabilidad persuasiva democrática en la que los ciudadanos participan evaluando el accionar de sus gobernantes. En materia de seguridad pública, la sociedad civil se ha divido en dos sectores: observatorios ciudadanos y población vulnerable. El primer sector ha construido un diálogo con sus gobernantes mientras evalúa su desempeño y, a partir de su gestión, establece prioridades de prevención del delito y combate contra la delincuencia. Sin embargo, es en el sector vulnerable de la esfera civil donde se gesta una serie de emociones, consideradas en el presente trabajo de suma importancia para contrastar un modelo de desconfianza hacia las autoridades en función de emociones negativas. Para tal propósito, se 1levó a cabo un estudio transversal con una muestra no probabilística de 270 residentes de una comunidad huasteca. Los análisis de normalidad $(C=3,211)$, confiabilidad (alfas $>0,60)$, adecuación $(K M O=$ $0,762)$, esfericidad $(\chi 2=13,14 ; 11 \mathrm{gl} ; p<0,001)$, validez $(\Phi>0,300)$, covarianza $(0,90<\Phi>0,10)$ y ajuste $(\chi 2=1,438 ; 3 g l, p<0,697 ; G F I=0,987 ; R M R=0,042$; Holter $=240, p<0,05 ;$ PRATIO $=0,300)$, muestran que el modelo estructural de trayectorias puede ser especificado para explicar la relación entre preocupación y desconfianza $(\beta=0,26)$. Con base en tales hallazgos se realizó una discusión con la Teoría de la Fiabilidad Social.

Palabras clave: ansiedad, preocupación, enojo, miedo, confianza.

Nota del autor

Javier Carreón Guillén, Departamento de Trabajo Social, Universidad Nacional Autónoma de México (UNAM)-Escuela Nacional de Trabajo Social (ENTS); María de Lourdes Morales Flores, Departamento de Trabajo Social, Universidad Autónoma del Estado de México (UAEM), unidad de Huehuetoca; Jorge Hernández Valdés, Departamento de Trabajo Social, UNAM-ENTS; Cruz García Lirios, Departamento de Trabajo Social, UAEM, unidad de Huehuetoca; José Marcos Bustos Aguayo, Departamento de Psicología, UNAM-Facultad de Estudios Superiores Zaragoza.

La correspondencia en relación con este artículo debe dirigirse a Javier Carreón Guillén, Departamento de Trabajo Social, UNAM-ENTS, Universidad 3000, Ciudad Universitaria, Coyoacán, 04350, Ciudad de México, D.F., México.

Correo electrónico: javierg@unam.mx 


\begin{abstract}
State and society have shifted from coercive relations totalitarian to democratic persuasive governance in which citizens participate in evaluating the actions of their rulers. In public safety, civil society has been divided into two sectors: observatories and vulnerable citizens. The first sector has built a dialogue with their leaders while evaluating their performance and from management sets priorities for crime prevention and combating crime. However, it is vulnerable sector in the civil sphere where a range of emotions which the present work has considered paramount to contrast a distrust of authorities based on negative emotions are conceived model. For this purpose, we conducted a cross-sectional study with a nonrandom sample of 270 residents of a community Huasteca. The analysis of normal $C$ $=3.211)$, reliability (alpha $>0.60)$, adequacy $(K M O=0.762)$, sphericity $(\chi 2=13.14 ; 11 g l, p<0.001)$, validity $(\Phi>0.300)$, covariance $(0.90<\Phi>0.10)$ and fit $(\chi 2=1.438 ; 3 g l, p<0.697, G F I=0.987$, $R M R=0.042$; Holter $=240, p<0.05 ;$ PRATIO $=0.300)$ show that the structural model paths can be specified to explain the relationship between concern and distrust $(\beta=0.26)$. From these findings a discussion with the Theory of Social Reliability was performed.
\end{abstract}

Keywords: anxiety, worry, anger, fear, confidence.

En el marco de la seguridad pública, conceptos tales como emotividad y fiabilidad resultan fundamentales para explicar la relación entre sociedad y Estado (Escobar de Morel, 2012). La seguridad pública es una construcción social inherente a la modernidad sólida; en contraste, la percepción de inseguridad es propia de la etapa moderna líquida (Araujo, 2012). La primera modernidad supuso una competencia por la legitimidad política, territorial, jurídica, racional, burocrática, productiva y autoritaria (Fabricant \& Postero, 2013); más tarde, una vez que el discurso legitimador fue sustituido por un escepticismo, la modernidad líquida produjo percepciones de riesgo, incertidumbre, azar, e inseguridad (Bauman, 2005). Se trata de un contexto donde la ciudadanía aspira a salvar su existencia del peligro asociado con la delincuencia (Bauman, 2008).
En tal contexto, el objetivo del presente estudio es explicar la relación entre sociedad y Estado con énfasis en las emociones negativas que determinan la desconfianza hacia las autoridades. Para tal propósito, se emplearon los inventarios de Inteligencia Emocional y Fiabilidad Social de García-Lirios (2012) con la finalidad de contrastar un modelo de trayectorias hipotéticas derivadas de la revisión de la literatura en referencia con los resultados obtenidos. Tal ejercicio permitió discutir las estructuras sociales que inhiben la participación ciudadana, ya que facilitan la contingencia de emociones negativas hacia las autoridades locales.

\section{Teoría de la personalidad emotiva}

Las emociones han sido definidas como reacciones motivacionales y cognitivas hacia un objeto, las cuales a menudo se traducen en discur- 
sos (Fazio, 2007). Es decir, las emociones son el resultado de experiencias que activan procesos neurocognitivos tales como el incremento de serotonina y dopamina, aunque tienen un origen social, pues se construyen a partir de las interrelaciones entre individuos y grupos (Redondo \& Pueyo, 2007). Debido a que las emociones han sido abordadas multidisciplinariamente, dos teorías han intentado explicar su naturaleza y relevancia social.

La Teoría de la Personalidad Emotiva (EPT, por sus siglas en inglés) de Eysenck (Eysenck, Payne, \& Derakshan, 2005) sostiene que el individuo atraviesa por tres procesos donde se determina su grado de emotividad con respecto a situaciones inciertas, inconmensurables e impredecibles:

- Extraversión. Disminución del sistema reticular; búsqueda de sensaciones, impulsividad e irritabilidad

- Neuroticismo. Baja afectividad negativa ante estrés, ansiedad, depresión u hostilidad.

- Psicologismo. Aumento de serotonina y dopamina; mayor o menor insensibilidad social, crueldad, agresividad

La EPT predice el surgimiento de emociones al considerar que los eventos de riesgo tales como secuestro, robo, extorsión, corrupción o violación están determinados por los niveles bajos de extraversión y neuroticismo así como el aumento de psicologismo (Fazio, 2011). Por el contrario, un incremento del sistema reticular y la afectividad positiva así como una disminución de serotonina y dopamina estarían vinculados con la aparición de emociones orientadas a la confianza personal (López \& Núñez, 2009). Es posible advertir que la EPT explica la naturaleza de las emociones con base en procesos internos del individuo, aunque tal aproximación contribuye al estudio de la personalidad en relación a la confianza.

\section{Teoría de la fiabilidad social}

Las relaciones entre ciudadanos y autoridades en un contexto de seguridad pública llega a explicarse con la Teoría de la Fiabilidad Social (RST, por sus siglas en inglés) de Giddens (2011), la cual plantea que la confianza de la ciudadanía en el Estado supone un proceso socio-histórico donde las acciones de instituciones encargadas de la seguridad propician una serie de emociones aglomerada en la fiabilidad (Muñoz \& Martínez, 2007). Empero, a diferencia de la confianza, sustentada en un contexto de seguridad y certidumbre, la fiabilidad asume que la incertidumbre e inseguridad son inherentes al Estado, en tanto que sus instituciones han dejado de ser coercitivas y ahora su función es más bien la persuasión de la ciudadanía. Es decir, el cambio en la relación Estado y sociedad civil derivó en el establecimiento de relaciones despersonalizadas (García-Lirios, 2006).

$\mathrm{Si}$ las emociones en lo general y la fiabilidad en lo particular son indicadores de una nueva relación entre Estado y ciudadanía, entonces, es menester revisar los estudios relativos a la ansiedad, enojo, preocupación, miedo y confianza para esclarecer las nuevas relaciones entre sociedad civil y autoridades. 
¿Seguridad pública o percepción de inseguridad? Estado de la cuestión o del conocimiento

El estado del conocimiento o de la cuestión señala una tendencia de los estudios sobre percepción de inseguridad a la investigación del impacto de los medios de comunicación en la opinión ciudadana y la construcción de una agenda pública (Véase tabla 4 en anexo). Las cifras que corresponden a instituciones gubernamentales no siempre coinciden con los datos proporcionados por organizaciones civiles (García-Lirios, 2012). Asimismo, se establecen diferencias en cuanto a la violencia perpetuada en escenarios laborales con respecto a espacios cotidianos en los que la discriminación es una causal en la comisión delictiva (Buker, 2011). Precisamente, mientras en los escenarios civiles la violencia es llevada a cabo por una persona cercana, en escenarios laborales la agresión es efectuada por motivos laborales en cuanto al relegamiento de tareas (Panster \& Castillo, 2007). En contraste, los homicidios perpetrados en contextos más cotidianos son cometidos en horarios nocturnos, mientras que los laborales se realizaron durante el horario de trabajo (GarcíaLirios, 2011).

Otras diferencias en cuanto a homicidas parecen mostrar que los ámbitos laborales son distintos del ambiente cotidiano en el cual los hombres que consumen algún estupefaciente cubren el perfil que las autoridades definen como causa externa a sus emociones, en tanto las mujeres, en lo general, llevan a cabo actos violentos derivados de su inestabilidad afectiva (Santana \&
Sánchez, 2010). Es lógico suponer que las diferencias entre los géneros nos llevan a pensar en características emotivas asimétricas entre homicidas, ya que algunos construyen símbolos de poder y otros de desesperanza (Dammert, Salazar, Montt, \& González, 2010).

Incluso, las diferencias sociodemográficas están relacionadas con las características socioeconómicas; se observan diferencias entre los estratos sociales bajo, medio y alto al momento de llevar a cabo algún delito (Díez-Sainz \& Alegre de Vega, 1986). En este sentido, la distribución de la riqueza parecería una causal del clima de violencia, debido a un malestar emocional por parte de la población con menores ingresos respecto al sector con mayores recursos financieros (Guerrero, 2007).

Empero, los asesinatos dolosos de extranjeros cometidos por adolescentes de barrios marginados, vulnerables o excluidos, parecen indicar que el descontento está centrado en un sector inestable emocional y laboralmente, más que en aquellos sectores donde se cuenta con un ingreso mínimo y constante (Laca, Santana, Ochoa, \& Mejía, 2011). La dimensión territorial de los homicidios o "ajuste de cuentas" parece sugerir que tal malestar deriva de una serie de intereses exacerbados por las ganancias que los actos delictivos implican (Cardona et al., 2005).

Algunos otros estudios pretenden vincular el origen étnico con la relación afectiva que la víctima tenía respecto a grupos diferentes a los de su pertenencia o referencia (Safaryk \& Jarvis, 2005). Otras investigaciones pretenden 
encontrar en las experiencias de infancia las causas por las cuales los delincuentes responden a procesos frustrantes o estresantes en torno a su vida y socialización (Britvic, Urlic, \& Definis-Gojanovic, 2006). En paralelo, la situación sociodemográfica y socioeconómica del delincuente está relacionada con su vida conyugal, dado que la mayoría de los actos delictivos revisados en una muestra de jóvenes homicidas correspondió con una inestabilidad de pareja (Marín-Fernández, Gallego-Caminero, Martín-Sanz, \& San Martín-Salazar, 1994). Más aún, la prevalencia de homicidios parece estar relacionada con espacios cerrados y poco concurridos, la interrelación parece inhibir los actos delictivos y facilitar la cooperación entre los transeúntes o usuarios (Santos, Barcellos \& Carvalho, 2006).

Respecto a la legitimidad de la seguridad pública, los escenarios de protesta social no sólo fungen como espacios de reflexión crítica o expresión pública, sino, además, implican la construcción de un movimiento disidente de la esfera civil en referencia al Estado y sus sistemas represores. Por ello, la percepción de inseguridad, a diferencia de la percepción de riesgo, emerge como un problema individual mientras que la inconformidad y desesperanza subyacen como problemáticas de orden social (Gámez, Santano, Matías, Roca, \& Tomey, 1999).

En un sentido opuesto, la correlación entre los casos de homicidios, género y estatus social durante un periodo de 10 años parece corroborar la hipótesis de que la violencia es una construcción social que se gesta a partir de la prevalencia de información circundante en cuanto a la rectoría del Estado, la diseminación de la paz pública y la disgregación de valores sociales (Hendricks, Jenkings, \& Anderson, 2007). De ahí que el núcleo central de las representaciones sociales en torno a las adicciones significa un proceso histórico en el cual la identidad y el uso de las drogas marcan una etapa particular en la historia de una comunidad o barrio (Londoño, Patiño, Cano, $\&$ Arias, 2007). Es decir, las representaciones sociales parecen ser el resultado de un proceso de significación grupal en el cual la información contribuye a su conformación, pero el efecto de las políticas y programas gubernamentales parece incipiente en diferentes localidades que ejercen el mismo estilo de administración de justicia (Hjalmarson, 2008).

$\mathrm{Si}$ las representaciones sociales de la violencia corresponden a grupos que utilizan diferentes medios para la construcción de su identidad, entonces, el núcleo central se debió haber formado en una edad temprana; empero, el sistema de justicia parece facilitar la construcción de símbolos y significados relativos a la socialización del delito, debido a que permite la interrelación entre menores infractores y castiga severamente a quienes tienen la mayoría de edad al momento de ser juzgados por un delito (Mendoza \& Sánchez, 2010). La clave de la formación de actitudes, construcción de representaciones $y$ establecimiento de identidades alusivas a la delincuencia puede 
encontrarse en las experiencias de menoscabo al momento de haber sido identificados como potenciales víctimas o delincuentes confesos (Áslund, Leppert, Starring, \& Nilsson, 2009).

En tal escenario, los medios de comunicación infiltran temas en la agenda personal, grupal, ciudadana, política y pública a través de frases o palabras que luego la opinión pública adopta e incorpora a su representación, habitus y discurso (García-Lirios, 2012). En este sentido, las representaciones sociales de la justicia y equidad versan en torno al otorgamiento de derechos más que al establecimiento de obligaciones y responsabilidades ciudadanas orientadas a la prevención del delito más que al combate frontal contra la delincuencia (Torregrosa, 2009). En consecuencia, las diferencias entre sexos hacen pensar que la construcción de la identidad de género masculina está asociada a la usurpación de bienes o recursos dada la competencia y la movilidad atribuidas. En contraste, la inestabilidad emocional justifica la comisión de un robo por parte de las mujeres, ya que embona con la identidad de género femenina en torno a su pasividad y victimización (Bolívar, Contreras, Jiménez, \& Chaux, 2010). Es decir, si los medios de comunicación difunden estereotipos de género que después serán recuperados por la ciudadanía, entonces, es posible anticipar que las respuestas preventivas son menos preferibles a las respuestas de combate en contra del crimen organizado. Es así como las diferencias de género están dimensionadas en cuanto a violencia, apoyo social, autocontrol, confrontación, responsabilidad, distanciamiento y evitación (Elizalde, 2010).

La ansiedad, el enojo, la preocupación, el miedo y la desconfianza como factores de estrés referentes a experiencias de agresión, robo, secuestro, extorsión, asesinato o violación (Fernández, Revilla, \& Domínguez, 2011), han establecido diferencias significativas entre hombres y mujeres, así como entre los grupos a los cuales pertenecen o quieren pertenecer al haber presenciado o sufrido alguna experiencia delictiva (Bolívar et al., 2010; Elizalde, 2010; Sánchez \& Cerezo, 2010), han relacionado los contextos socioeconómicos y territoriales con el manejo de emociones (Gibson, Sullivan, Jones, \& Piquero, 2010) y, sobre todo, han establecido una relación directa y positiva entre la confianza hacia las autoridades y la gobernanza local (Ruiz, 2010; Silveira, Assunçào, Figeiredo, \& Beato, 2010). Tales relaciones de experiencias cara a cara también fueron corroboradas en experiencias delictivas a través de tecnologías de información (Álvarez et al., 2011).

Ahora bien, las investigaciones en torno a la inseguridad han avanzado por un sendero donde el estudio de las emociones y fiabilidades parece mostrar que los contenidos de la televisión inciden en mayor medida que algún otro mensaje (Fernández et al., 2010). En otra investigación, el contexto discursivo parece haber influido en el autocontrol; a medida que los temas relativos a la seguridad pública se conformaban por símbolos y significados de identidad generaban percepciones de utilidad en materia de video- 
vigilancia o algún otro dispositivo de alarma (Gunter, 2008). En un escenario tal, con delincuencia vigilada, la gente parece desarrollar una fiabilidad social para con sus autoridades. Por el contrario, cuando la acción policiaca no garantiza la justicia y se aproxima a la opacidad, corrupción o impunidad, la desconfianza hacia el Estado se exacerba (McCombs, 2006). Tal proceso es reforzado por la difusión que la prensa lleva a cabo ante el incremento de la violencia local y afecta la percepción de desesperanza en los residentes (García-Lirios, 2007). Una consecuencia directa de la fiabilidad social es la generación de emociones, sentimientos $\mathrm{y}$ afectos desfavorables a la paz pública, ya que las diferencias entre los géneros incrementa la percepción de inseguridad (Oliva, Hernández, \& Calleja, 2010). Más aún, el desconocimiento de una situación o relación violenta parece ser otro efecto del contexto de seguridad pública, el cual propicia heurísticos de convivencia que inciden sobre la calidad de las relaciones interpersonales (Ramírez \& Núñez, 2010).

En materia de opinión pública, son dos los efectos que generan los medios de comunicación sobre sus audiencias al momento de difundir información relativa a la seguridad pública, la rectoría del Estado y la organización civil. Se trata del encuadre de verosimilitud y el encuadre de verificabilidad; el primero es una consecuencia del sesgo mediático y el segundo, una acción concreta derivada de la disonancia cognitiva (Federico, Gómez, \& Piacenza, 2010). Es decir, los lectores cuyo estatus socioeconómico es alto son influidos por aquellas noticias que infunden temor, mientras que los sectores considerados víctimas de la delincuencia están más cercanos a la satisfacción ciudadana al momento de leer noticias alusivas al combate contra la delincuencia (Oliva et al., 2010). En el caso de los delincuentes, sus necesidades económicas destacan sobre las necesidades afectivas del perfil de sus víctimas, pues aquellas les llevaron a cometer acciones de riesgo y despreocupación de su seguridad personal (García-Lirios, Montero y López-Lena, Bustos-Aguayo, Carreón-Guillén, \& Hernández-Valdés, 2013).

La complejidad de la seguridad pública, en tanto políticas públicas y programas preventivos, así como sus consecuencias en la percepción de inseguridad por parte de la sociedad civil, hacen que las propuestas de intervención tengan resultados poco eficaces; mientras se promueve la paz pública a partir de valores cívicos, la delincuencia organizada está infiltrada en las esferas políticas e incide directamente en la administración e impartición de la justicia a través de sobornos (Silveria et al., 2010).

Incluso, los sectores vulnerables al crimen organizado asumen que los actos delictivos están plenamente justificados si de subsistencia se trata, o bien, las acciones que promueven la identidad local al estar permeadas de actos discriminatorios y lesivos para la convivencia social son consideradas como parte de los usos y costumbres de una comunidad (Marina \& Sánchez, 2010). Tales emociones y creencias empatan con las atribuciones a la identidad de 
género en la que los hombres se consideran más móviles que las mujeres por el simple hecho de cometer un mayor número de delitos inherentes a sus necesidades económicas e inexorables a sus estados emocionales (GarcíaLirios, 2012). Ello implica una distorsión de dos realidades paralelas, la relativa a los medios de comunicación y la experimentada en las calles. Se trata de escenarios donde los usuarios de los espacios construyen símbolos que les permiten interactuar o transitar de un lugar a otro sin advertir las consecuencias de sus actos (Álvarez et al., 2011). Ello supondría que un ciberdelincuente está más cercano a una realidad alterna que lo aproxima a cometer un delito en la vida cotidiana si para ello es necesario representar un escenario similar al que las tecnologías informativas le permiten. De ahí que el incremento de los homicidios obedece más bien a un perfil de víctima que corresponde con el que los medios de comunicación se han encargado de difundir durante el periodo que va de 2000 a 2010 (Gutiérrez, Hernández, \& Viguri, 2011).

En efecto, los medios de comunicación parecen incidir en las expectativas que generan por la difusión de sus contenidos y las percepciones que se tienen de las autoridades (García-Lirios, Carreón-Guillén, HernándezValdés, Bautista-Miranda, \& Méndez-Martínez, 2013). Esto es así porque en el caso de la prensa, la difusión de la seguridad pública, la rectoría del Estado y la percepción de inseguridad ciudadana corresponden a periodos electorales en los que se advierten incrementos y disminuciones paulatinas de los temas y contenidos.

En resumen, los estudios psicológicos y sociológicos en materia de seguridad e inseguridad evidencian el impacto del sesgo informativo sobre las expectativas de las audiencias. Una consecuencia de tal relación es la percepción de la rectoría del Estado en cuanto a seguridad pública se refiere. Sin embargo, los instrumentos para medir las emociones relativas a la seguridad pública han sido desarrollados por ser considerados como evidencia de evaluación de políticas públicas o como un diagnóstico del estrés ciudadano ante la acción gubernamental. A partir de tales criterios, los instrumentos han ponderado directamente la opinión pública en relación al delito soslayando la cotidianidad en la que está inmersa la sociedad civil y que se deriva de las decisiones gubernamentales de procuración de justicia.

En este tenor, las experiencias cotidianas en el transporte, durante un paseo o una llamada telefónica estarían relacionadas con acontecimientos de violencia tales como asaltos, secuestros, extorsiones, asesinatos o desapariciones que podrían disminuir o incrementar la confianza hacia los instrumentos de seguridad pública tales como policía judicial, ministerio público o tecnologías de vigilancia. En tales procesos, las emociones determinarían la evaluación de las autoridades a partir de activar experiencias directas o indirectas con la delincuencia.

Si la Teoría de la Personalidad Emotiva advierte que las experiencias cotidianas 
incluyen emociones relativas a la seguridad personal, entonces, según lo establece la Teoría de la Fiabilidad Social, éstas podrían vincularse con la desconfianza hacia las autoridades en situaciones de riesgo e incertidumbre

¿Cuáles son las relaciones entre la ansiedad, la preocupación, el enojo y el miedo ante la acción gubernamental de prevención del delito o combate a la delincuencia?

\section{Hipótesis}

Las experiencias emocionales cotidianas de los ciudadanos están directamente relacionadas con sus evaluaciones de las autoridades en materia de prevención del delito o combate a la delincuencia (Véase figura 1). En tal sentido, en un evento de riesgo e incertidumbre, la ansiedad estaría relacionada con la preocupación (hipótesis 1), ya que un incremento en ésta primera podría generar una desconfianza en las autoridades (hipótesis 2), empero, una mayor preocupación por la seguridad personal estaría vinculada a un aumento en la desconfianza de combate a la delincuencia (hipótesis 3). Ahora bien, la ansiedad podría incrementar su efecto sobre la desconfianza hacia la acción gubernamental a través del enojo (hipótesis 4), aunque la preocupación también podría explicar la variabilidad de la desconfianza a través del miedo (hipótesis 5). Es decir, un mayor enojo propiciaría una mayor desconfianza (hipótesis 6), pero un excesivo miedo generaría una menor desconfianza porque la ciudadanía se sentiría indefensa ante la delincuencia y sus autoridades serían un refugio (hipótesis 7). No obstante, existen otras emociones tales como la decepción que podría influir sobre la desconfianza, la asertividad o la venganza sobre el enojo así como la indignación, la autoestima y la depresión sobre el miedo.

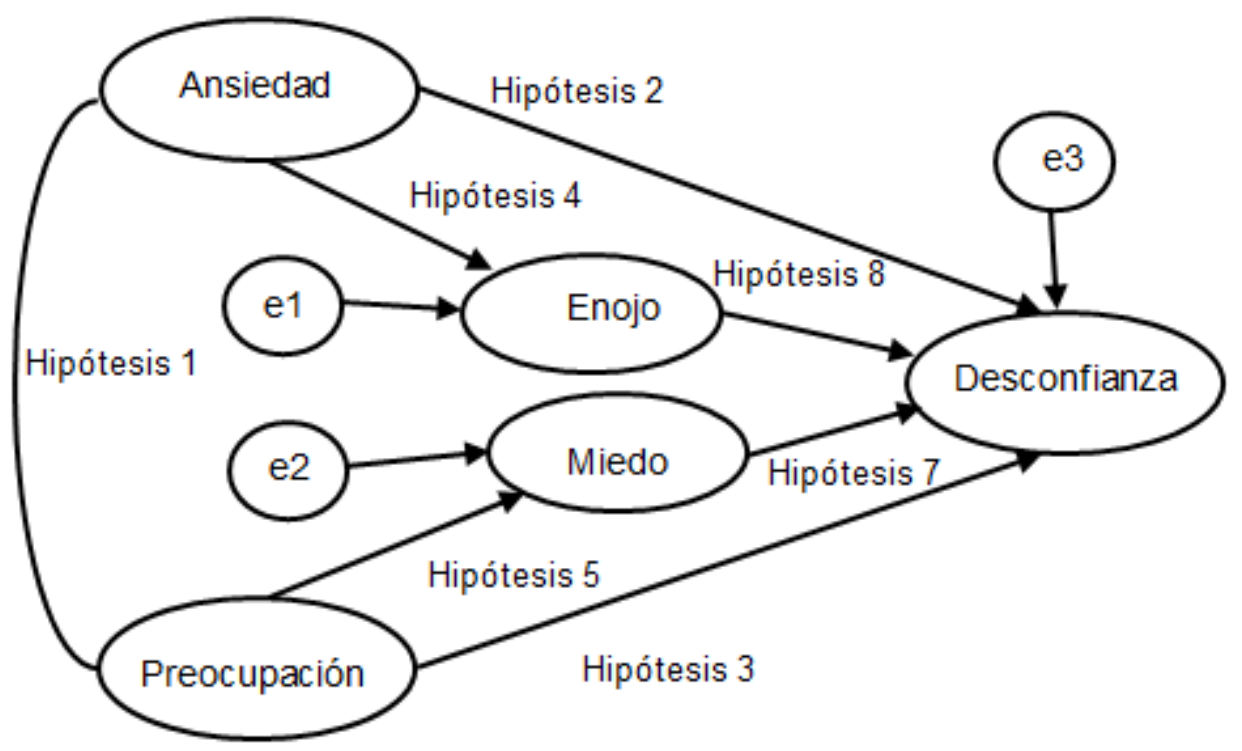

Figura 1. Trayectorias de relaciones entre emociones y evaluaciones. 


\section{Método}

\section{Diseño}

Se llevó a cabo un estudio correlacional y transversal.

\section{Participantes}

La muestra estuvo conformada por 270 habitantes (155 mujeres y 115 hombres), seleccionados intencionalmente de una comunidad huasteca $(M=23.6$ años cumplidos, $D E=9.3$ años cumplidos) e ingreso económico mensual ( $M=670 \mathrm{USD}, D E=10.8 \mathrm{USD})$. El $68 \%$ declaró conocer a sus autoridades locales mientras que $16 \%$ dijo que no sabía quiénes eran sus autoridades y $16 \%$ no contestó. Respecto a los comicios, 44\% dijo que votaría por una autoridad local si ésta garantizará empleo y seguridad, pero sólo $12 \%$ votaría por una autoridad que sólo se comprometiera con la creación de empleos, $20 \%$ votaría si sus autoridades sólo propusieran resguardar a la comunidad y $24 \%$ señaló que no votaría por alguna autoridad que se comprometiera con la creación del empleo y/o la seguridad local.

\section{Instrumento}

Se utilizaron las Escalas de Inteligencia Emocional y Fiabilidad Social de García-Lirios (2012). Se llevó a cabo la confiabilidad y validez de cinco variables correspondientes a ansiedad, definida como el grado de prevención del delito en situaciones cotidianas de transporte (cinco ítems con opciones de respuesta que van desde nunca hasta siempre); preocupación, entendida como el nivel de percepción de riesgo (cinco ítems con opciones que van desde muy frecuente hasta nada frecuente); enojo, establecida como la frecuencia de olvido de pertenencias (cinco ítems con opciones que van desde muchas veces hasta ninguna vez); miedo, ponderado por la prevalencia de episodios desconcertantes (cinco ítems con opciones que van desde muchísimo hasta nada) y escala de desconfianza, medida por la tendencia de atribución de responsabilidad a las autoridades (cinco ítems con opciones que van desde totalmente de acuerdo hasta totalmente en desacuerdo).

\section{Procedimiento}

Se contactó a la muestra con el registro municipal de caficultores; se les llamó por teléfono para realizar la encuesta en las instalaciones de la asociación de emprendedores. Se les informó sobre el propósito de la investigación y se les entregó la encuesta haciendo énfasis en la confidencialidad de sus respuestas. En los casos en los que había una tendencia a la misma opción de respuesta, o bien, la ausencia de respuesta, se les solicitó que anotaran al reverso las razones por las cuales contestaron con la misma opción de respuesta o en su caso la ausencia de ella. Los datos fueron capturados en el Programa Estadístico para Ciencias Sociales (SPSS, por sus siglas en inglés, versión 20) y los análisis de ecuaciones estructurales se estimaron con la ayuda de programa de Análisis de Momentos Estructurales (AMOS, por sus siglas en inglés, versión 6).

\section{Análisis de datos}

Normalidad. La distribución normal fue estimada a partir del parámetro de curtosis mul- 
tivariable en la cual valores inferiores a cinco fueron considerados evidencia de normalidad. La significancia del parámetro se calculó con el estadístico bootstrap cuyo valor fue cercano a cero. Los valores de curtosis se ubican en el intervalo de $-3 \mathrm{a}+3$, que indican una distribución normal.

Confiabilidad. La estimación de la consistencia interna se llevó a cabo a partir de las correlaciones entre ítem y sub-escala. El parámetro alfa de Cronbach con valores superiores a .60 se consideró evidencia de consistencia interna.

Validez. Se realizó un análisis factorial exploratorio de componentes principales con rotación varimax y pruebas tanto de esfericidad como de adecuación con los parámetros de Bartlett y Kayser-Meyer-Olkin. Los pesos factoriales superiores a .300 fueron considerados como evidencia de correlación entre reactivos y factores.

Covariación. Kline (2010) señala que una vez especificado el modelo (elaboración de relaciones hipotéticas entre indicadores $y$ constructos), se procede a identificar el modelo (en el caso donde el programa pueda determinar la estructura teóricamente supuesta). En este sentido, la covariación entre indicadores implica sólo variables continuas que se miden en niveles de intervalos estandarizados en los cuales la media es igual a cero y la desviación equivale a la unidad. No obstante, la covariación "phi" (Ф) sólo requiere de variables con niveles de medición ordinal, donde los valores se agrupan de mayor a menor o a la inversa. Estos valores de covariación reflejan una relación lineal entre las variables y un valor residual cercano al cero si los errores se mantienen constantes.

Estructura. Se seleccionó el parámetro chi cuadrada para probar la hipótesis de ajuste y, en su caso, re-especificar el modelo, ya que son recomendables valores cercanos a la unidad para inferir el ajuste del modelo hipotético al modelo estructural. En el caso del parámetro residual RMSEA, es recomendable un valor cercano a cero, pero al estar determinado por otros factores no especificados ni identificados en el modelo, se asume como aceptable un valor cercano a cero, pero no mayor a .08 .

Ajuste. El estadístico chi cuadrada cercano a la unidad y nivel de significancia mayor a .05 fue considerado como evidencia de ajuste. Sin embargo, debido a que la chi cuadrada es sensible al tamaño de la muestra para el contraste de las hipótesis, se consideró un valor cercano a la unidad para los índices de bondad de ajuste y próximo a cero para los índices residuales.

\section{Resultados}

La normalidad, confiabilidad y validez, se estimaron para establecer las covarianzas entre los factores, como se muestra en las tablas 1 y 2. Los valores cercanos a la unidad fueron considerados como evidencia de colinealidad mientras que los próximos a cero fueron entendidos como relaciones espurias. 
Tabla 1

Descriptivos de los ítems y estructura factorial de las escalas de García (2012) en la presente muestra

Descriptivos Matriz de componentes rotada

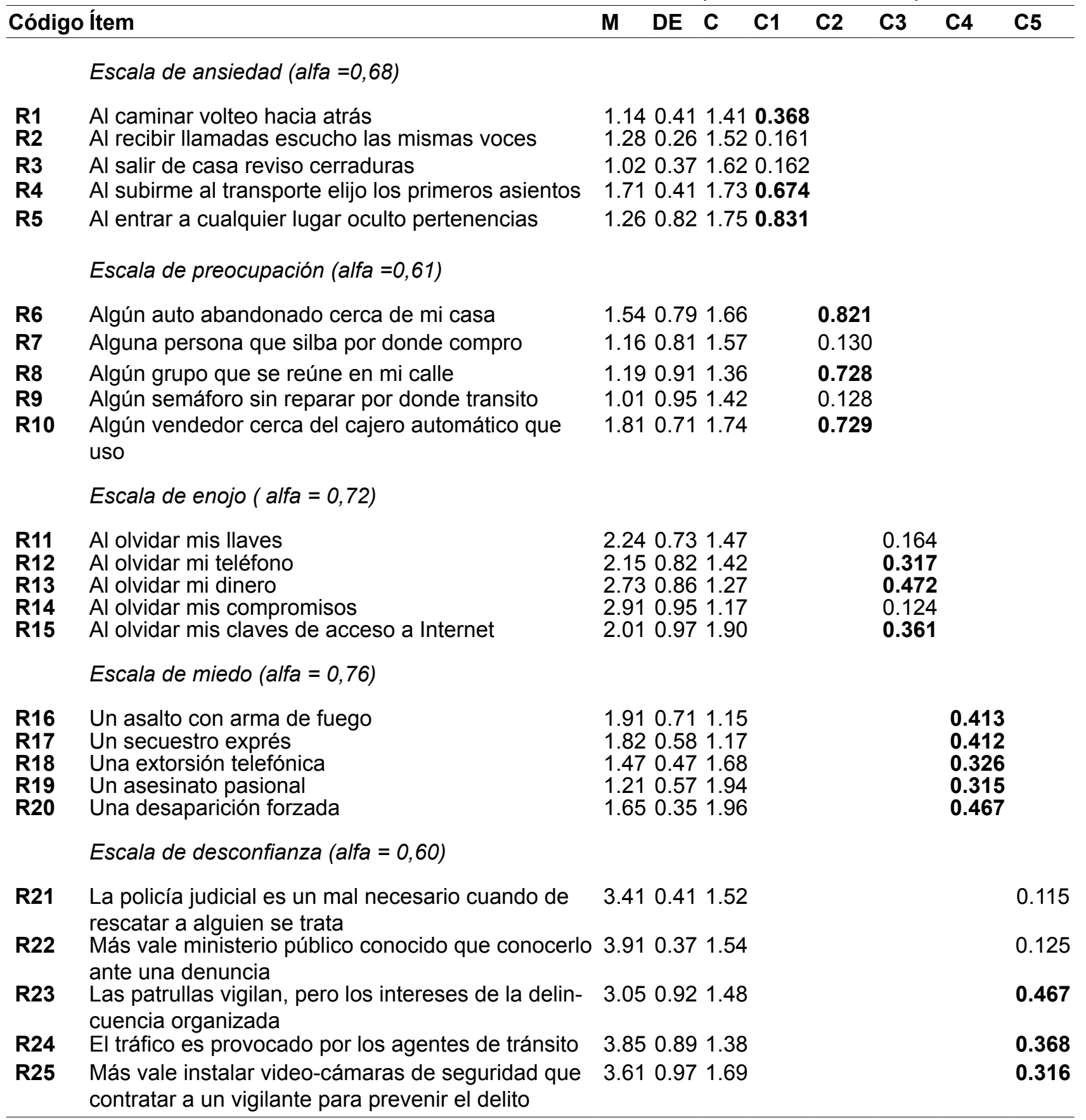

Rango de los ítems del Inventario de ansiedad: $0=$ nunca, $1=$ casi nunca, $2=$ a veces, $3=$ casi siempre, $4=$ siempre: del Inventario de preocupación: $3=$ muy frecuente, $2=$ poco frecuente, $1=$ muy poco frecuente, $0=$ nada frecuente; del Inventario de miedo: 4 = muchísimo, $3=$ mucho, $2=$ poco, $1=$ muy poco, $0=$ nada; del Inventario de desconfianza: $4=$ totalmente de acuerdo, 3 de acuerdo, $2=$ en desacuerdo, $1=$ totalmente en desacuerdo. $N=270$ Curtosis multivariada de Mardia $=3,211$, índice de adecuación de la muestra de $K M O=.762$, Prueba de la esfericidad de Bartlett: $\chi 2$ [13gl] = 18,08, $p<0,001$. Método de extracción: Componentes Principales. Método de rotación: Varimax. Porcentaje de varianza explicada: 53\% por C1 (Ansiedad), 45\% por C2 (Preocupación), 39\% por C3 (Enojo), 32\% por C4 (Miedo) y 27\% por C5 (Desconfianza). Significación de los parámetros: ns $p>.05{ }^{*} p \leq .05,{ }^{* *} p \leq .01,{ }^{* * *} p \leq .001$ 
Tabla 2

Covarianzas entre los factores

\begin{tabular}{llllll}
\hline & Ansiedad & Preocupación & Enojo & Miedo & Desconfianza \\
\hline Ansiedad & 1.496 & & & & \\
Preocupación & -0.129 & 1.360 & & & \\
Enojo & -0.023 & 0.076 & 1.502 & & \\
Miedo & 0.093 & -0.236 & -0.074 & 1.050 & \\
Desconfianza & 0.117 & 0.173 & -0.115 & 0.060 & 1.466 \\
\hline
\end{tabular}

La asociación negativa entre ansiedad y preocupación $(\Phi=-.129)$ denota una ambivalencia de emociones que se genera ante hechos cotidianos de inseguridad. En contraste, la relación positiva entre la ansiedad para con la desconfianza $(\Phi=.117)$ supone que un incremento en la ansiedad está vinculado con un aumento en la desconfianza hacia las autoridades. Respecto a la preocupación, su correlación negativa con el miedo $(\Phi=-.236)$ alude a que la ciudadanía está en un estado de ambivalencia ante la acción gubernamental en materia de prevención del delito o combate a la delincuencia. Sin embargo, el vínculo positivo de la preocupación con la desconfianza $(\Phi=$ .173) advierte un estado de indefensión, ya que la ciudadanía se preocupa cada vez más cuando su confianza disminuye en quienes la gobiernan. Por ello, la asociación entre enojo y desconfianza resultó negativa ( $\Phi=-.115)$, lo cual sugiere que una mayor confianza está ligada con un menor enojo.

No obstante que las covarianzas especificaron algunas relaciones entre los factores emocionales, se calculó la estructura de las trayectorias supuestas (ver figura 2). Los resultados muestran que la desconfianza es explicada positivamente por la preocupación $(\beta$ $=.26)$ y negativamente por el enojo $(\beta=-.24)$. Sin embargo, la incidencia de otros factores (e.g. la decepción entre otras emociones), no incluidos en el modelo, inciden sobre la desconfianza $(\beta$ $=.38)$.

Para contrastar cada una de la hipótesis, se calcularon los parámetros de dependencia, ajuste y residuales (ver tabla 3 ).

Debido a que el primer estadístico $\left(X^{2}=\right.$ $1.438 ; 3 g l ; p=.697)$ es sensible al tamaño de la muestra, se estimó el Índice de Bondad de Ajuste $(G F I=.987)$, así como el residuo cuadrático medio $(S M R=0,042)$, índice de Holter $(p>0,05$; $n=240$ ), el error de aproximación cuadrático medio $(R M S E A=.000)$ y el Índice de JamesMulak-Brekk $(P R A T I O=0,300)$. Tales valores se consideraron como evidencia de aceptación de todas las hipótesis excepto la 4 y 7 , pues sus valores están cercanos a cero y fueron asumidos como relaciones espurias. Es decir, entre la ansiedad y el enojo $(\beta=.06)$ y entre el miedo y la desconfianza $(\beta=.06)$ hay otros factores (e.g. 


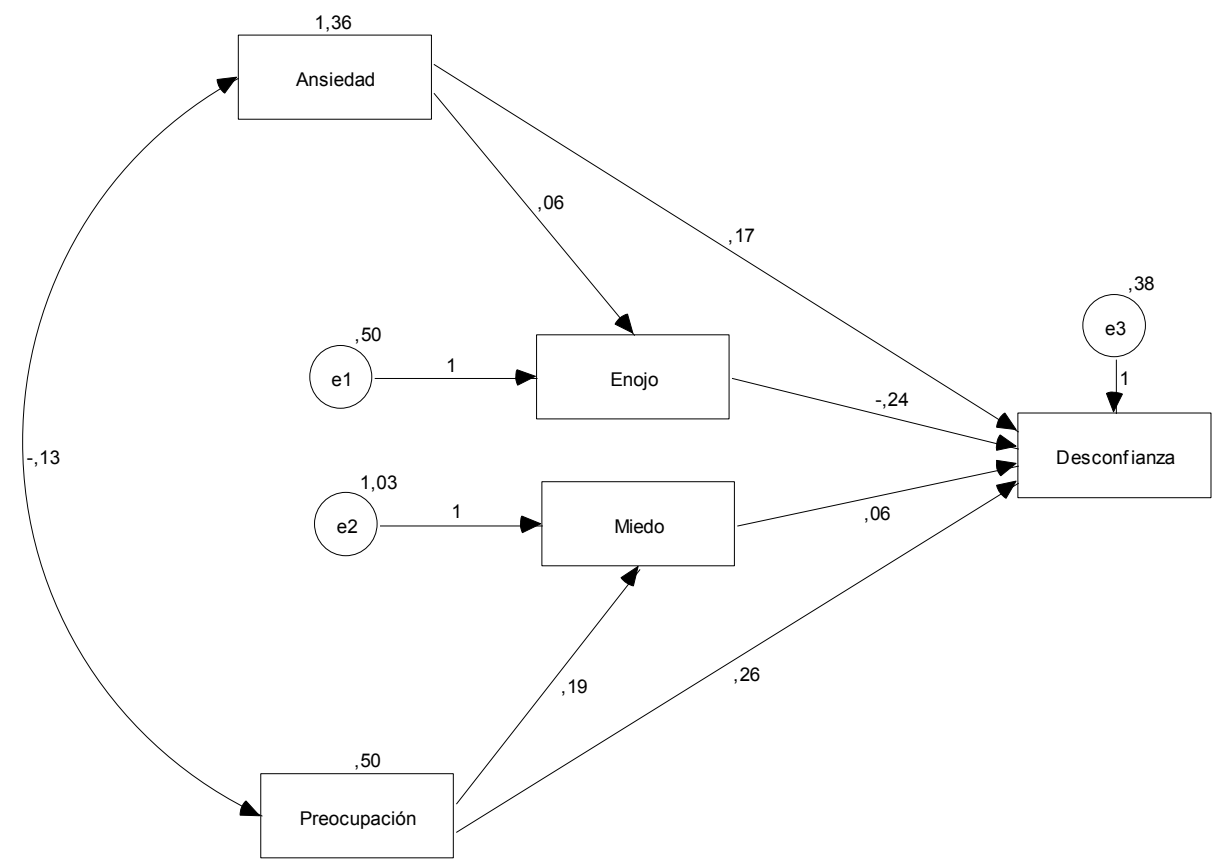

Figura 2. Estructura de relaciones entre emociones y evaluaciones.

\section{Tabla 3}

Parámetros de ajuste

\begin{tabular}{lllllllllll}
\hline Modelo & $\boldsymbol{X}^{\mathbf{2}}$ & $\mathbf{G I}$ & $\boldsymbol{P}$ & $\boldsymbol{R M R}$ & Holter & GFI & $\boldsymbol{R} M S E A$ & PRATIO & PNFI & PCFI \\
\hline Especificado & 1.438 & 3 & 0.697 & 0.042 & 240 & 0.987 & 0.000 & 0.300 & 0.278 & 0.300 \\
Independiente & 10.926 & 10 & 0.030 & 0.171 & 41 & 0.859 & 0.150 & 1.000 & 0.000 & 0.000 \\
\hline
\end{tabular}

la asertividad, la venganza, la autoestima o la depresión por mencionar algunos), que podrían influir sobre dichas relaciones.

\section{Discusión}

El presente estudio ha establecido un modelo de trayectorias de relaciones entre factores emocionales que explican la desconfianza hacia las autoridades en situaciones cotidianas de inseguridad. Sin embargo, otros factores emocionales (e.g. decepción, temperamento, indefensión) podrían estar influyendo sobre la confianza hacia la acción gubernamental en materia de prevención del delito o combate contra la delincuencia.

- La presente investigación encontró una relación negativa entre el enojo y la 
desconfianza hacia las autoridades. A medida que las personas incrementan su molestia consigo mismos, aumentan su confianza hacia sus autoridades.

- En el presente estudio se encontró que entre el miedo al secuestro, asalto, desaparición, violación o asesinato y la desconfianza hacia la acción policiaca otras variables inciden en esta relación.

En referencia al estudio de Oliva et al. (2010) donde se encontraron asociaciones entre el enojo dirigido a un grupo y el temperamento, o respecto al trabajo de Malone (2010), en el cual la confianza hacia las autoridades está en función del miedo a la delincuencia, tales estudios relativos al enojo y al miedo como determinantes de la confianza hacia la acción gubernamental deberán ser complementados con otros factores.

En referencia a la Teoría de la Personalidad Emotiva de Eynseck (Eynseck et al., 2005) y la Teoría de la Fiabilidad Social de Giddens (2011), el presente estudio ha encontrado que la ansiedad, está vinculada con la desconfianza, que a diferencia de la fiabilidad, se expresa en situaciones de seguridad y certidumbre. Tal hallazgo y distinción son fundamentales para explicar la relación entre la esfera civil y la esfera política; mientras la fiabilidad parece estar circunscrita a emociones y conductas de riesgo entre la sociedad civil, la desconfianza se vincula con la ansiedad, preocupación, enojo y miedo entre ciudadanos y servidores públicos.
No obstante, el estudio de las emociones ha avanzado hacia su análisis multidisciplinario, en tanto, la fiabilidad parece consolidarse como fenómeno social en el cual los procesos psicológicos estarían confinados a la confianza personal, pero se alejarían de la fiabilidad social.

Empero, los estudios sobre seguridad pública distan mucho de las investigaciones que se realizan a partir de las percepciones de inseguridad (ICESI, 2010). Es decir, ambas esferas, civil o política, parecen estar mediadas por poderes fácticos tales como televisión, radio o prensa, elementos que insisten en volver a la rectoría del Estado como eje de la seguridad pública y símbolo de la percepción ciudadana frente a la prevención del delito y el combate contra la delincuencia (Kliksberg, 2008). Precisamente, se trata de campos discursivos de poder en los que la seguridad pública se ha transformado en percepción de inseguridad (Bourdieu, 2011). Tales campos de poder inhiben las libertades, oportunidades, capacidades y responsabilidades que las esferas civiles requieren para construir un escenario de seguridad pública, ya no a partir de la rectoría del Estado, sino de la discusión pública y el debate ciudadano (Sen, 2011). Es decir, los estudios sobre percepción de inseguridad deben incluir en sus análisis al Estado y sus políticas de comunicación, transparencia y acceso a la información (Páez, 2006). En la medida que la ciudadanía tome decisiones en materia de seguridad pública en corresponsabilidad con sus 
representantes, la gobernanza territorial y local permitirá avanzar en el estudio de la percepción de inseguridad, ya no como inteligencia emocional o fiabilidad social, sino como un sistema de participación deliberativa en la cual la discusión de las políticas de seguridad sea un tema central en la agenda pública (Rosas, Calderón, \& Campos, 2012).

\section{Conclusión}

El debate multidisciplinar, donde la seguridad pública y la percepción de inseguridad explican las nuevas relaciones entre autoridades públicas y sociedad civil, abre la discusión en torno a la inclusión de las emociones en modelos predictores de la confianza y la fiabilidad social, sin embargo, estos modelos deberán incluir emociones tales como decepción, asertividad, autoestima, depresión e indignación, las cuales podrían incidir sobre otras variables sociales como habitus, participación o capitales.

La construcción de un modelo multidisciplinar de las emociones y la fiabilidad permitirá explicar procesos de índole electoral, en los cuales los expertos en marketing político anticiparán las preferencias electorales y las intenciones de voto por parte de los ciudadanos con respecto a partidos, candidatos y plataformas políticas. Tal empresa contribuirá a la construcción de un sistema democrático en el que la ciudadanía delibere sus decisiones electorales a fin de establecer una gobernanza donde el diálogo con la clase gobernante será inminente para la toma de decisiones y acciones públicas y locales.
En la construcción de la democracia participativa, las emociones de la ciudadanía son un antecedente fundamental para la emergencia de la fiabilidad y la confianza hacia las autoridades.

\section{Referencias}

Álvarez, G. D., Núñez, P. J., Álvarez, P. L., Dobarro, G. A., Rodríguez, P. C., \& González, C. P. (2011). Violencia a través de las tecnologías de la información y la comunicación en estudiantes de secundaria. Anales de Psicología, 27, 221-231.

Araujo, X. (2012). Una revisión básica sobre conceptos y teorías de gobernabilidad. Geoenseñanza, 9, 203-212.

Áslund, C., Leppert, J., Starring, B., \& Nilsson, K. (2009). Subjective social status and shaming experiences in relation to adolescent repression. Archive Pediatrics Adolescent Medical, 163, 55-61.

Badejo, A., \& Oluyemi, S. (2012). Predisposing factors to youth involvement in electoral violence in Lagos metropolis. Journal of Emerging Trends in Educational Research and Policing Studies, 3, 312-316.

Bauman, Z. (2005). Vida Líquida. Barcelona: Paidós.

Bauman, Z. (2008). Vida de consumo. Barcelona: Anthropos.

Bolívar, C., Contreras, J., Jiménez, M., \& Chaux, E. (2010). Desentendimiento moral y dinámicas del robo escolar. Revista de Criminología, 52, 243-261. 
Bourdieu, P. (2011). Las estrategias de reproducción social. México: Siglo XXI.

Britvic, D., Urlic, I., \& Definis-Gojanovic, M. (2006). Juvenile perpetrators of homicides and attempted homicides -a case control study. Anthropology, 30, 143-147.

Buker, H. (2011). Formation of self control: Gottfredson and Hirschi's general theory of crime and beyond. Aggression and Violence Behavior, 16, 265-276.

Cardona, M., García, H., Giraldo, C., López, M., Suárez, C., Corcho, D., \& Posada, C. (2005). Escenarios de homicidios en Medellín, Colombia entre 1990-2002. Revista Cubana de Salud Pública, 31, 302-310.

Dammert, L., Salazar, F., Montt, C., \& González, P. (2010). Crimen e inseguridad. Indicadores para las Américas. Santiago: Flacso-Bid.

Díez-Sainz, J. A., \& Alegre de Vega, C. (1986). Aspectos humanos y profesionales del A. T. S. y de U. V. I. Tribuna Sanitaria, 32, 23-25. Elizalde, C. A. (2010). Estudio descriptivo de las estrategias de afrontamiento del bullying en profesorado mexicano. Education \& Psychology, 8, 353-372.

Escobar de Morel, M. (2012). La participación ciudadana, análisis a partir de la transición democrática. Revista Internacional de Investigación en Ciencias Sociales, 8, 119-140.

Eysenck, M., Payne, S., \& Derakshan, N. (2005). Trail anxiety, visuo-spatial processing and working memory. Cognition \& Emotion, 19(8), 1214-1228.
Fabricant, L., \& Postero, N. (2013). Contested bodies, contested states: Performance, emotions, and new forms of regional governance in Santa Cruz, Bolivia. Journal Latin American and Caribbean Anthropology, 18, 187211.

Fazio, R. H. (2007). Attitudes as object-evaluation associations of varying strength. Social Cognition, 25, 603-637.

Fazio, R. H. (2011). A fundamental conceptual distinction gone unnoticed. En R. Arkin (Ed.), Most underappreciated: 50 prominent social psychologists describe their most unloved work (pp. 72-76). New York: Oxford University Press.

Federico, L., Gómez, R. \& Piacenza, P. (2010). Homicidios diarios. Análisis del discurso periodístico sobre homicidios por armas de fuego. Buenos Aires (Argentina) 2001-2002. Salud Colectiva, 6(3), 295-312.

Fernández, C., Revilla, J., \& Domínguez, R. (2010). Emotions elicited by television violence. Scientific Journal of Media Literary, 36, 97-104.

Gámez, P. M., Santano, M. A., Matías, B. S., Roca, S. S., \& Tomey, S. M. (1999). Estudio del clima laboral en cuatro unidades de críticos de un hospital. Enferm Intensiva, 10(3), 120-128.

García-Lirios, C. (2006). Una modelación de las variables que explican el impacto de los eventos terroristas sobre el comportamiento humano. Entelequia, 1, 141-150. 
García-Lirios, C. (2007). Un programa de manejo de riesgos. Alternativas en Psicología, 12, 105-138.

García-Lirios, C. (2008). La percepción de inseguridad en la Ciudad de México. Científica de Psicología, 7, 52-68.

García-Lirios, C. (2011). Una aproximación sistémica a la realidad política. Enfoques, 23, 63-78.

García-Lirios, C. (2012). Estructura perceptiva de inseguridad en universitarios. Liberabit, 17, 1-10.

García-Lirios, C., Carreón-Guillén, J., Hernández-Valdés, J., Bautista-Miranda, M., \& Méndez-Martínez, A. (2013). La cobertura de la prensa en torno a la inseguridad migratoria durante elecciones presidenciales. $R e$ vista de Comunicación de la SEECI, 17(30), 57-73.

García-Lirios, C., Montero y López-Lena, M., Bustos-Aguayo, J. M., Carreón-Guillén, J., \& Hernández-Valdés, J. (2013). La inseguridad migratoria en los medios impresos de la Ciudad de México. Reflexiones, 92(1), 159173.

Gervais, W. (2011). Findings the faithless: Perceived atheist prevalence reduces antiatheist prejudice. Personality and Social Psychology Bulletin, 37, 543-556.

Gibson, C., Sullivan, C., Jones, S., \& Piquero, A. (2010). Does it take a village? Assessing neighborhood influences of children's selfcontrol. Journal of Research in Crime and Delinquency, 47, 31-62.
Giddens, A. (2011). La constitución de la sociedad. Bases para la teoría de la reestructuración. Buenos Aires: Amorrortu.

Guerrero, V. R. (2007). Segregación sociourbana y representaciones sociales de inseguridad en dos comunas de Santiago de Chile. Cultura y Representaciones Sociales. 3, 151-168.

Gunter, B. (2008). Media violence: Is there a case for causality? American Behavioral Scientist, 51(8), 1061-1022.

Gutiérrez, G., Fernández, S., \& Viguri, R. (2011). Homicidios en menores de 15 años de edad, México. 2000-2010 informe preliminar. Boletín Médico del Hospital Infantil de México, 68, 253-258.

Hendricks, S., Jenkings, L., \& Anderson, K. (2007). Trends in work place homicides in the U. S., 1993-2002: A decade of decline. American Journal of Industry Medicine, 50, 316-325.

Hjalmarson, R. (2008). Does capital punishment have a local deterrent effect on homicides. American Law \& Economic Review, 12, 310-334.

Instituto Ciudadano de Estudios Sobre la Inseguridad [ICESI]. (2010). Informe anual de la inseguridad. México: ICESI.

Jamshidi, H., Khazael, J., Pourmostafa, L., \& Khoshkorodi, P. (2012). Analyzing direct and indirect impacts of emotional intelligence on employees sell efficacy using the sem: A case study at the university of Isfahan. Journal of Basic and Applied Scientific Research, 12, 9710-9716. 
Kline, R. B. (2010). Principles and practice of structural equation modeling (3er ed.). New York: The Gilford Press.

Kliksberg, B. (2008). ¿Cómo enfrentar la inseguridad en América Latina? La falacia de la mano dura. Nueva Sociedad, 215, 4-17.

Laca, A., Santana, H., Ochoa, Y., \& Mejía, J. (2011). Percepción de bienestar social, anomia, interés e impotencia política en relación con las actitudes hacia la democracia. Liberabit, 17, 7-18.

Lau, R., Sigelman, L., \& Brown, I. (2007). The effects of negative political campaigns: A meta-analytic reassessment. Journal of Politics, 69, 1176-1209.

Leaf van Boven, M., \& Campbell, T. (2010). Stigmatizing materialism: On stereotypes and impressions of materialistic and experiential pursuits. Personality and Social Psychology Bulleting, 36, 551-556.

Londoño, U. S., Patiño, G. V., Cano, B., \& Arias, Z. J. (2007). Representaciones sociales de los jóvenes de la ciudad de Medellín sobre el consumo de sustancias psicoactivas en relación con sus escenarios. Informes Psicológicos, 9, 11-40.

López, M., \& Núñez, G. M. (2009). Psicopatía versus trastorno antisocial de la personalidad. Revista Española de Investigación Criminológica, 7, 1-17.

Malone, M. (2010). The verdict is in: The impact of crime on public trust in Central American Justice System. Journal of Politics and Latin American, 3, 99-128.
Marín-Fernández, B., Gallego-Caminero, G., Martín-Sanz, E., \& San Martín-Salazar, B. (1994). Análisis bibliométrico de la producción científica de la enfermería de cuidados intensivos. Enferm Intensiva, 5(4), 166-173.

Marina, N., \& Sánchez, P. A. (2010). Representaciones sociales acerca de la delincuencia que tienen las menores de edad institucionalizadas en un centro de reeducación de la ciudad de Bogotá. Diversitas: Perspectivas en Psicología, 6, 275-295.

McCombs, M. (2006). Estableciendo la agenda. Madrid: Paidós.

Mittal, S., Chanana, A., Rai, A., \& Dalal, J. (2005). Medicolegal study of mechanical injuries in culpable homicidies. JIAMP, 27, 226-230.

Muñoz, G. D., \& Martínez, P. J. (2007). Aproximaciones conceptuales a las políticas juveniles: Desmodernización, anticipación moral y política de vida. Universitas Humanística, 64, 67-91.

Oliva, M. F., Hernández, P. M., \& Calleja, B. N. (2010). Validación de la versión mexicana del inventario de expresión de ira estado rasgo (STAXI-2). Acta Colombiana de Psicología, 13, 107-117.

Osakpa, D. (2012). Political violence and secondary school education in Nigeria: A case study of bette-bendi people of cross river state. International Journal of Research in Engineering and Social Sciences, 2, 189206. 
Páez, A. (2006). La participación ciudadana y su relación con el acceso a la información pública. Ra Xhimai, 3, 611-640.

Panster, W., \& Castillo, H. (2007). Violencia e inseguridad en la Ciudad de México: Entre la fragmentización y la politización. Foro Internacional, 47, 577-615.

Ramírez, R. C., \& Núñez, L. D. (2010). Violencia en la relación noviazgo en jóvenes universitarios: Un estudio exploratorio. Enseñanza e Investigación en Psicología, 15, 273-283.

Redondo, S., \& Pueyo, A. (2007). La psicología de la delincuencia. Papeles del Psicólogo, 28, 147-156.

Rey, L., Extremera, N., \& Pena, M. (2011). Perceived emotional intelligence, self esteem and life satisfaction in adolescent. Psychological Interventions, 20, 227-234.

Romeu, L. \& Piacenza, P. (2010). Homicidios diarios. Análisis del discurso periodístico sobre homicidios por armas de fuego. Buenos Aires (Argentina) 2001-2002. Salud Colectiva, 6, 295-312.

Rosas, F., Calderón, J. \& Campos, H. (2012). Elementos conceptuales para el análisis de la gobernanza territorial. Quivera, 14, 113-136.

Ruiz, P. J. (2010). Eficacia colectiva, cultura ciudadana y victimización: Un análisis exploratorio con sus relaciones con diversas medidas de miedo al crimen. Acta Colombiana de Psicología, 13, 103-114.

Safaryk, M., \& Jarvis, J. (2005). Examining attributes of homicides. Toward quantifying qualitative values of injury severity. Homicide Studies, 9, 1-21.

Sánchez, L. C., \& Cerezo, R. F. (2010). Variables personales y sociales relacionadas con la dinámica bullying en escolares de educación primaria. Journal of Research in Education Psychology, 8, 1015-1032.

Sánchez, S., Mendoza, B., Chibisov, S., Bruno, H., Mendoza, I., López, A., \& Bazán, G. (2008). Far and circatransyearly rhithmic death incidense due to violent sex homicides in México City. International Journal of Geronto - Gereatrics, 11, 103-109.

Santana, C. L.,\& Sánchez, P. M. (2010). La presencia del familiar en el momento del fallecimiento mejora la calidad del morir en la unidad de cuidados intensivos. Enferm Intensiva, 21(2), 83-84.

Santos, S., Barcellos, C., \& Carvalho, M. (2006). Ecological analysis of the distribution al sociospatial context of homicides in Porto Alegre, Brazil. Health \& Place, 12, 3847.

Sen, A. (2011). The idea of justice. Cambridge: Harvard University Press.

Silveira, A., Assunçào, R., Figeiredo, B., \& Beato, C. (2010). Impact of the staying alive program on the reduction of homicides in a community in Belo Horizonte. Revista Saùde Pública, 44, 1-6.

Torregrosa, J. N. (2009). Representaciones sociales en torno al concepto de equidad y justicia de los conciliadores y las conciliadoras 
en equidad de las unidades de medicación y conciliación de Bogotá. Misión Jurídica, 2, 181-211.

Vaughn, M., \& Perron, B. (2011). Substance users carreers and antisocial behavior: A biosocial life-course perspective. En M. Delisi \& K. Beaver (Coord.), Criminology theory: A life course approach. Florida: Nelson Universities and Colleges.

Vázquez, C., \& Martínez, C. (2011). Género y profesión como moduladores de la modificación de los estereotipos. Anales de Psicología, 27, 427-434.

Velandia, M. A., \& Rodríguez, B. R. (2010). Estereotipos femeninos y preferencia de consumo. Universitas Psychologica, 10, 47-59. 


\section{ANEXO}

Tabla 4

Estado de la cuestión

\begin{tabular}{|c|c|c|}
\hline Año & Autor & Hallazgos \\
\hline 2005 & $\begin{array}{l}\text { Cardona, } \\
\text { García, } \\
\text { Giraldo, } \\
\text { López, Suárez, } \\
\text { Corcho, \& } \\
\text { Posada }\end{array}$ & $\begin{array}{l}\text { Demostraron ocho dimensiones de la violencia en torno a } 55,365 \text { homicidios. La } \\
\text { dimensión territorial se refiere a los homicidios personales y colectivos en los que } \\
\text { los "ajustes de cuentas" implican "reivindicaciones grupales" por el "control de la } \\
\text { plaza" entre los cárteles de la droga. La dimensión ideológica política en la cua } \\
\text { la implementación del terror a través del asesinato de una figura política es su } \\
\text { característica principal. En la dimensión de intolerancia social, los homicidios son } \\
\text { un instrumento de limpieza étnica. En la dimensión del narcotráfico, los homicidios } \\
\text { son llevados a cabo debido a la disputa por el comercio de estupefacientes. En la } \\
\text { dimensión apropiativa de bienes, los homicidios son el medio para conseguir un } \\
\text { fin que es arrebatar la propiedad privada con lujo de violencia. En la dimensión } \\
\text { de conflictos personales, los homicidios son perpetrados por causas externas a } \\
\text { las emociones humanas y por causas internas relacionadas con las emociones } \\
\text { humanas. En la dimensión moral y económica, los homicidios tienen un origen } \\
\text { impulsivo. Finalmente, en la dimensión indiscriminada convergen e interactúan } \\
\text { las dimensiones anteriores haciendo más difícil la clasificación de los homicidios } \\
\text { Llevaron a cabo un estudio descriptivo en el que encontraron alrededor de un } \\
93 \text { por ciento para los casos de homicidios en contra de hombres. Entre } 20 \text { y } 24 \\
\text { años tenían, cerca de } 25 \text { por ciento, quienes fueron privados de la vida, donde e } \\
\text { "ajuste de cuentas" fue el móvil principal para su ejecución, además, pertenecían } \\
\text { a un estatus socioeconómico muy bajo. El lugar en el que fueron encontrados sin } \\
\text { vida también tiene un índice de marginalidad extremadamente bajo y el arma de } \\
\text { fuego fue el principal instrumento del delito. A pesar de estos datos, la ciudad de } \\
\text { Medellín fue clasificada como de bajo a mediano riesgo, ya que las zonas de alto } \\
\text { o extremo riesgo fueron minoría en relación con los demás barrios de la urbe. En } \\
\text { este sentido, los barrios con mayor riesgo de muerte fueron; Poblado, Laureles, } \\
\text { América, Guayabal, Robledo, San Javier, } 12 \text { de Octubre, Castilla, Buenos Aires, } \\
\text { Villa Hermosa, Manrique. Araniuez, Santa Cruz, Candelaria y Popular. }\end{array}$ \\
\hline
\end{tabular}

2005 Mittal, Channan, Rai, \& Dalal

Establecieron como causas principales de los homicidios: laceraciones y heridas en zonas periurbanas de Estados Unidos, Europa y Asia. A medida que los homicidios se intensificaban, los casos se sistematizan en torno a patrones de agresión y violencia del victimario y las víctimas.

2005 Safaryk \& Jarvis

Demostraron diferencias significativas entre la raza del delincuente con respecto a la composición étnica de su vecindad, la edad del delincuente en referencia con la lesión provocada a la víctima, la distancia del delincuente respecto a la composición étnica de su vecindad y el conocimiento de la víctima por parte del delincuente en relación con la composición física de la víctima.

2006 Britvic, Urlic, \& Definis

Demostraron diferencias significativas entre menores perpetradores de homicidios con respecto a robos con arma de fuego, rechazo parental y abuso físico. Es decir, los homicidios, a diferencia del latrocinio, se explicaban de acuerdo con un perfil criminológico en el que se evidenciaba la socialización de la violencia como un factor determinante de comisión de un delito en contra de la integridad física de un perfil específico de víctima. 
2006 Matías

2006 Saenz

2006 Santos, Barcellos, \& Carvalho

2007 Hendricks, Jenkings, \& Anderson

2007 Lau, Sigelman, \& Brown

2007 Londoño, Patiño, Cano, \& Arias

2008 Hjalmarson

2008 Sánchez, Mendoza, Chibisov, Bruno, Méndoza, López, Vargas, Peña, \& Bazán

2009 Áslund, Leppert, Starring, \& Nilsson
Las representaciones sociales de la protesta se indagaron en las noticias de prensa, ya que se asumieron como indicadores de procesos simbólicos y comunicativos los cuales son componentes esenciales del sentido y saber común. De este modo, la legitimidad del gobierno y la represión del Estado son los símbolos en torno a los cuales se construye el pensamiento social.

Describió el perfil sociodemográfico del homicidio con porcentajes. El $97 \%$ fue hombre, $40 \%$ tenía entre 18 y 24 años al momento de cometer el crimen, 35 por ciento estaba soltero, pero 33 vivía en unión libre, 31 por ciento laboraba en el sector de los servicios y alrededor de 45 por ciento residía en zonas rurales. Respecto a las víctimas; 82 por ciento fue hombre, 37 por ciento fue privado de la vida en su casa habitación y 34 por ciento, en la calle.

Establecieron las dimensiones espaciales de los homicidios a partir de tres categorías: alta, media y baja prevalencia. Los porcentajes de ocurrencia muestran un nivel medio de prevalencia. Sin embargo, el nivel alto de prevalencia crece más sistemáticamente en referencia a la alta y baja prevalencia.

Describieron la disminución de homicidios ocurridos de 1993 al año 2002 en los rubros de sexo, edad y raza en los lugares de trabajo de la industria estadounidense. Esta tendencia también se observó en los tipos de ocupaciones y oficios. Incluso, en torno al tipo de eventos y circunstancias de los homicidios, se observó la misma tendencia a la baja en el número de casos.

Demostraron efectos mínimos de las campañas sucias en contra de un candidato o partido a través del recuerdo de propuestas, interés en la campaña, conocimiento de candidatura, afectación a los comicios, afecto por el atacante, necesidad de afecto, intención de voto y cambio de preferencia electoral.

Las representaciones sociales adquieren un carácter histórico, ya que los informantes asociaron la práctica discursiva con las sustancias a través de los escenarios de consumo.

Estableció el efecto directo, negativo y significativo entre la localidad en donde se cometieron los homicidios y el número de víctimas, entre la región con mayor prevalencia de homicidios y las ejecuciones locales, entre las ciudades con mayor índice de homicidios y la prevalencia de ejecuciones. Al realizar comparaciones entre las tendencias de homicidios ocurridos en las localidades no encontró diferencias significativas con respecto a las administraciones de justicia anteriores y la actual.

Demostraron diferencias significativas entre rangos de edad femeninos y masculinos con respecto a la incidencia de homicidios. En la medida en que las edades se incrementaban había diferencias significativas, al parecer quienes cometían un delito por vez primera tenían mayores probabilidades de reincidir si tal edad en la que fueron juzgados estaba cercana a la adolescencia. En contraste, aquellos delincuentes con mayoría de edad cuidaban su reincidencia porque ello implicaba una pena mayor que si hubiesen cometido un delito en la minoría de edad.

Las experiencias de menoscabo y baja condición social interactuaban con la depresión. El grupo más vulnerable fue el de niños y niñas con respecto a otros rangos de edad. A mayores experiencias de menoscabo, se incrementan las probabilidades de depresión en grupos de bajo estatus económico. 
2009 García

2009 Torregrosa

2009 Zacarés et. al.

2010 Bolívar, Contreras, Jiménez, \& Chaux

2010 Elizalde

2010 Fernández, Revilla, \& Domínguez

2010 Gibson, Sullivan, Jones, \& Piquero

2010 Leaf van Boven, \& Campbell

2010 Malone
La percepción mediática del accionar gubernamental se relacionó con la percepción de inseguridad pública $(\beta=.36 ; p<.01)$. Es decir, los medios de comunicación parecen haber incidido en la percepción del delito en la muestra de estudio. En este sentido, la percepción de inseguridad parece estar mediada por algunas variables o categorías de orden mediático tales como "video-vigilancia", "lugar teniente", "crimen organizado" o "cártel de la droga". La fiabilidad social mediada por algún dispositivo de información o comunicación parecen incrementar su influencia en las expectativas que la gente se construye acerca de su seguridad personal y grupal.

Las representaciones sociales fueron diversificadas. En el caso de la justicia se refiere al otorgamiento de derechos, en el caso de la equidad, se refiere a la apertura para la posibilidad de justicia.

La identidad moratoria fue explicada por la autoestima $(\beta=-.37 ; p<.05)$. El apoyo de pares incidió en la identidad de logro $(\beta=.19 ; p<.05)$. La identidad difusiva fue afectada por la edad $(\beta=-.25 ; p<.05)$. También la edad influyó en la identidad cerrada $(\beta=-.26 ; p<.05)$.

Establecieron diferencias significativas entre hombres y mujeres $(F=8.09 ; p=$ $.005)$, así como entre entrevistas y grupos focales $(F=49.61 ; p=.000)$ respecto al robo. A decir de los participantes masculinos, el latrocinio se debe a factores externos a las necesidades de los hombres, mientras que el robo es el resultado de una inestabilidad emocional en el caso de que lo cometiesen las mujeres.

Estableció diferencias significativas entre edad y sexo respecto a estilos de afrontamiento de la violencia; apoyo social, autocontrol, confrontación, responsabilidad, distanciamiento y evitación. Se trata de factores relacionados con los estereotipos de género en los que parece haber una tendencia a atribuir movilidad al género masculino y pasividad al femenino.

Las emociones (nerviosismo, ansiedad, disgusto, repugnancia, horror, enojo, miedo, catarsis e insensibilidad) inmediatas y diferidas de los contenidos de la televisión propician narrativas de responsabilidad y culpa. Son construcciones derivadas de discursos mediáticos en los que se enlazan valores, actitudes y acciones. La primera reacción ante la inseguridad y la violencia es emocional.

Encontraron efectos significativos del contexto del barrio sobre el autocontrol, aunque las características individuales en interrelación con las características del barrio diluyeron la varianza explicada. En el caso de los estilos parentales de supervisión $(r=.07)$, entusiasta $(r=-.08)$ y hostil $(r=-.10)$, correlacionaron significativamente con el autocontrol.

Las personas estigmatizaron más a los individuos materialistas que a quienes se aproximan a vivir experiencias no materialistas. La segunda actividad fue mayormente preferida sobre la primera.

En ciudades con una alta tasa de criminalidad, la confianza en el sistema de justicia está determinada por el temor a la delincuencia local $(\beta=-.146 ; p=.000)$, la evaluación de la acción institucional $(\beta=.737 ; p=.000)$, la edad $(\beta=-.0004 ; p$ $=.05)$, el tamaño del municipio $(\beta=-.052 ; p=.05)$. La confianza hacia la policía es influida por la victimización personal $(\beta=-.175 ; p=.000)$, la delincuencia local $(\beta=-.154 ; p=.0000)$, la evaluación de la acción gubernamental $(\beta=.437 ; p=$ .001). La confianza en los derechos humanos está incidida por la delincuencia local $(\beta=-.091 ; p=.0000)$, la evaluación institucional $(\beta=.558 ; p=.000)$, el sexo masculino $(\beta=-.158 ; p=.000)$ y el tamaño del municipio $(\beta=-.046 ; p=.05)$. En el caso de las ciudades con un bajo índice delictivo, destaca la evaluación de las instituciones como predictor de la confianza en el sistema de justicia $(\beta=$ $.585 ; p=.000)$, la policía $(\beta=.567 ; p=.000)$ y los derechos humanos $(\beta=.324$; $p=.000)$. La atención a las noticias en la radio incidió sobre la confianza en el sistema $(\beta=.078 ; p=.010)$ y los derechos humanos $(\beta=.112 ; p=.05)$. En 
2010 Malone

2010 Marina

2010 Oliva, Hernández, \& Calleja

2010 Ramírez \& Núñez

2010 Romeu \& Piacenza el caso del seguimiento de la delincuencia en la prensa, influyó negativamente en la confianza al sistema $(\beta=-.091 ; p=.05)$, la policía $(\beta=-.092 ; p=.05)$ y los derechos humanos $(\beta=-.129 ; p=.05)$. En ciudades con una alta tasa de criminalidad, la confianza en el sistema de justicia está determinada por el temor a la delincuencia local $(\beta=-.146 ; p=.000)$, la evaluación de la acción institucional $(\beta=.737 ; p=.000)$, la edad $(\beta=-.0004 ; p=.05)$, el tamaño del municipio $(\beta=$ $-.052 ; p=.05)$. La confianza hacia la policía es influida por la victimización personal $(\beta=-.175 ; p=.000)$, la delincuencia local $(\beta=-.154 ; p=.0000)$, la evaluación de la acción gubernamental $(\beta=.437 ; p=.001)$. La confianza en los derechos humanos está incidida por la delincuencia local $(\beta=-.091 ; p=.0000)$, la evaluación institucional $(\beta=.558 ; p=.000)$, el sexo masculino $(\beta=-.158 ; p=.000)$ y el tamaño del municipio $(\beta=-.046 ; p=.05)$. En el caso de las ciudades con un bajo índice delictivo, destaca la evaluación de las instituciones como predictor de la confianza en el sistema de justicia $(\beta=.585 ; p=.000)$, la policía $(\beta=.567 ; p=$ $.000)$ y los derechos humanos $(\beta=.324 ; p=.000)$. La atención a las noticias en la radio incidió sobre la confianza en el sistema $(\beta=.078 ; p=.010)$ y los derechos humanos $(\beta=.112 ; p=.05)$. En el caso del seguimiento de la delincuencia en la prensa, influyó negativamente en la confianza al sistema $(\beta=-.091 ; p=$ $.05)$, la policía $(\beta=-.092 ; p=.05)$ y los derechos humanos $(\beta=-.129 ; p=.05)$.

Las representaciones sociales están relacionadas con valoraciones en torno a la delincuencia. Se formaron a partir de la manifestación simbólica y cotidiana como forma de conocimiento social. Es decir, la delincuencia es considerada como un medio de subsistencia y materializa como un instrumento de subsistencia.

Los deseos de expresar ira correlacionaron con la expresión externa de ira (.616; $p<.05)$ y con el control externo de la ira $(-.271 ; p<.05)$. El sentimiento de ira con el temperamento iracundo $(.598 ; p<.05)$ y con el control externo de la ira $(-.301 ; p$ $<.05)$. El temperamento iracundo con la expresión externa $(.618 ; p<.05)$ y con el control externo $(-.387 ; p<.05)$. La reacción de ira con la expresión externa $(.479$; $p<.05)$ y con el control externo $(-.142 ; p<.05)$. El control interno con la expresión externa $(-.209 ; p<.05)$. Por último, la expresión interna con la expresión externa (.412). Encontraron diferencias significativas entre hombres y mujeres con respecto al sentimiento de ira $(t=1.992 ; p<.05)$, el temperamento iracundo $(t=-2.112 ; p$ $<.05)$ y el control interno $(t=-2.965 ; p<.05)$.

Establecieron la percepción social de la violencia en el noviazgo a partir de entrevistas semi-estructuradas en las cuales descubrieron que dicha percepción está distorsionada y confusa a un grado tal que los entrevistados no lograron reconocer una situación de violencia.

Utilizó siete categorías de análisis para establecer los estilos de difusión y tematización de noticias. El análisis estableció la forma y el contenido de dos diarios de circulación nacional "El Clarín" y "La Nación”. Mientras el primer periódico incluía un estilo retórico popular, el segundo rotativo ajustaba su discurso a los eventos de violencia. Ambos coincidían en difundir la idea de inseguridad pública, en el caso del segundo diario, los asesinatos tuvieron una mayor cobertura. En torno a las conclusiones sobre los robos o asaltos, "El Clarín" excluía la opinión popular y el discurso gubernamental de su línea editorial, en el caso de "La Nación" evidenciaban su búsqueda de la verdad más que de la verosimilitud pública. Finalmente, respecto al tema de crímenes personales, el primer rotativo fue más sensacionalista en su contenido y el segundo fue más sensacionalista en su forma. El primer periódico sustentaba sus opiniones con discursos científicos y el segundo con discursos de género. Ambos enfocaban sus discursos en los aspectos emocionales descriptivos, más que los hechos, importaban las circunstancias. "El Clarín" adoptó una lógica de verosimilitud y "La Nación" una lógica de verificación. Ambas lógicas se complementan, ya que relatan los hechos de violencia homicida de un modo popular y objetivo en uno y otro periódico. 
2010 Ruiz

2010 Sánchez \& Cerezo

2010 Silveria, Assuncao, Figueredo, \& Beato

2010 Velandia \& Rodríguez

2011 Álvarez, Núñez, Álvarez, Dobarro, Rodríguez, \& González

2011 Gervais
El nivel socioeconómico correlacionó con el temor al delito (-.149), eficacia colectiva (.191), cultura ciudadana (.269), victimización (-.117), clima emocional (.274). Asimismo, la victimización se asoció con temor al delito (.201), eficacia colectiva (.258), cultura ciudadana (.223), satisfacción con la policía (-.136), clima emocional (.3999). Por su parte, el temor al delito se relacionó con eficacia colectiva (-.264), cultura ciudadana (-.315), satisfacción con la policía (-.242), con la victimización (.170) y el clima emocional (-.475). La eficacia colectiva se vinculó con cultura ciudadana (-554), satisfacción con la policía (.229) y el clima emocional (.382). La cultura ciudadana correlacionó con la satisfacción con la policía (.358), la victimización (-.142) y con el clima emocional (.567). La satisfacción con la policía se asoció con la victimización (.114) y el clima emocional (.333). Por último, la victimización, con el clima emocional (-.295).

Encontraron diferencias entre agresores y víctimas. Los primeros manifestaron necesidades económicas y sociales de integración escolar y los segundos, necesidades afectivas parentales. A medida que se cumplen características de sexo, edad y escolaridad se incrementan las probabilidades de riesgo y vulnerabilidad en torno a la violencia bullying.

Implementaron un programa de prevención de homicidios en cinco fases. En la primera fase, se concientizó a la población que habita las favelas de Belo Horizonte sobre el programa, se registraron en un periodo de doce meses 65 homicidios. En la segunda fase, el número de homicidios se redujo a seis debido a que el programa se llevó a cabo en colaboración y con el resguardo de la policía. En la tercera fase, se adiestró a los residentes de las favelas para su defensa personal en caso de presentarse algún ataque, se obtuvo un incremento en el número de homicidios que alcanzó las siete víctimas. En la cuarta fase, el programa se enfocó en la estructura social de creencias y valores con énfasis en la prevención de robo con violencia, se incrementaron a 13 homicidios durante el periodo. En la quinta y última fase, los homicidios se incrementaron a 43 y el programa incluyó el ofrecimiento de empleo temporal. Cabe señalar que el programa fue más exitoso en favelas no violentas en comparación con las favelas violentas. Principalmente, en el área de Morro das Piedras, el número de homicidios obtuvo el índice más alto. Prevención del delito implementado en una favela de violencia media resultó poco significativo. El programa en otras favelas más violentas de la ciudad de Belo Horizonte. El número de homicidios antes y después del programa no varió significativamente.

Establecieron asociaciones significativas entre las preferencias de consumo y los estereotipos femeninos. De este modo, la mujer sexy se asoció con la preferencia masculina y la mujer inteligente con la preferencia femenina. El estereotipo de ama de casa no se asoció con ningún tipo de preferencia masculina o femenina.

Establecieron correlaciones positivas entre la violencia cotidiana y la violencia a través de las Tecnologías de Información y Comunicación. Encontraron diferencias significativas entre sexos y entre centro y periferia espacial. A medida que los usuarios de las redes digitales incrementaban sus horas de sesión, las diferencias entre la realidad cotidiana y la reconstrucción mediática se difuminaban.

El anti-ateísmo es menor en países ateos, el ateísmo prevaleciente está asociado con los prejuicios anti-ateos. Los recuerdos de ateísmo están asociados con la desconfianza hacia los ateos. 
2011 Gutiérrez, Hernández, \& Viguri

2011 Rey Extremera, \& pena

2011 Vaughn \& Perron

2011 Vázquez \& Martínez

2012 Badejo \& Oluyemi

\section{García}

2012 Jamshidi, Khazael, Pourmostafa, \& Khoshkorodi

2012 Osakpa

2013 Fabricant \& Postero

2013 García
Describieron la tendencia a la alza de los homicidios durante el periodo 2000-2010 en el que hubo un incremento de alrededor de 16 por ciento. En el año 2000 se cometieron 10,735 homicidios que representaron una tasa de 11 por ciento, para el año 2010 fueron privados de la vida 29,598 víctimas que representaron una tasa de 27 por ciento. El mayor porcentaje se identifica entre los grupos de 25 a 44 años con una tasa del 48 por ciento. En el caso de los grupos menores de 15 años, aquellos que tienen menos de un año representan un incremento de su tasa en alrededor del 7 por ciento. En términos generales, la tendencia se ha incrementado discretamente durante el periodo del estudio. La frecuencia de los episodios violentos fue influida por la creencia en torno a que ser hombre es mejor que ser mujer $(\beta=-.20 ; p<.05)$ y la creencia de que un buen esposo es el que provee al hogar tuvo una incidencia positiva $(\beta=.17 ; p<.05)$.

La autoestima determinó directamente la satisfacción de vida $(\beta=0.51 ; p<0.01)$. Del mismo modo, la inteligencia emocional en su rubro de reparación de daños incidió sobre la autoestima $(\beta=0.23: p>0.01)$ y sobre la satisfacción vital $(\beta=$ $0.15 ; p<0.05)$.

La dependencia a las sustancias adictivas y el crimen están determinados por los estilos de vida.

La información relativa a la ocupación y el desempeño influyen sobre los juicios sesgados. A medida que los casos en torno a delitos del fuero común se incrementaban, el proceso de penalización estaba sesgado conforme a las características sociodemográficas y económicas de los inculpados.

Diferencias por género respecto a desempleo $(t=5.98)$ y armamentismo $(t=5.18)$. A medida que la formación de opiniones y actitudes hacia la seguridad pública aumentaba sus valores, la tendencia al armamentismo se intensificaba al igual que el desempleo entre quienes apoyaban el tráfico de armas para defensa personal o la de sus familiares.

La percepción mediática del accionar gubernamental incidió positivamente sobre la percepción de la inseguridad pública $(\beta=.36 ; p<.001)$.

La conciencia de sí mismo incidió en la inteligencia emocional $(\beta=0.88)$, seguido de la auto-motivación $(\beta=0.79)$. Auto-regulación $(\beta=0.69)$ y habilidades sociales $(\beta=0.63)$. Es decir, el auto-concepto parece ser un factor explicativo de comportamientos relativos a la socialización de primer y segundo orden en el aula.

Existe una relación entre la violencia sociopolítica y la educación de la escuela. Al parecer la socialización de la violencia hacia las autoridades y gobernantes se inculcaba en el aula mientras que el respeto a instituciones civiles se mantenía estable, sin cambio alguno con respecto a la clase política.

Las estrategias de protesta construyeron una identidad disidente a los gobiernos local y federal en torno a la distribución de los recursos para el desarrollo agrícola de la región. Las huelgas de hambre resultaron ser eficaces para construir una identidad victimizada que difumina las desigualdades respecto al acceso a créditos.

El sesgo de los medios impresos respecto a la inseguridad migratoria se caracterizó por un encuadre significativamente menor en referencia al enmarcado en torno a otros ámbitos de seguridad nacional y regional. Es decir, la difusión de la inseguridad migratoria en los medios de comunicación parece corroborar el supuesto según el cual los medios impresos construyen una agenda pública a partir de periodos electorales federales y comicios locales. 